(0.03), cloxacillin (0.07), erythromycin (0.13), fluconazole (0.08), Fosfomycin (0.09), itraconazole (0.04), linezolid (0.07), metronidazole (0.04) and vancomycin (0.05).

Conclusion and relevance Analysing the demographic characteristics of the neonatal population, the DDD of the antimicrobial group can be standardised, this allows establishing a conversion factor with respect to the adult DDD. A new study to confirm the validity of designed neonatal DDD and hence the conversion factor between neonatal DDD and adult DDD is underway.

\section{NP-020 ANTINEOPLASTIC AND OTHER HAZARDOUS DRUGS: RISK POTENTIAL AND EXPOSURE - LESS IS MORE!}

A Burch*, R Pfeuti, J Mack, G Vella, F Negrini. Cantonal pharmacy of Zurich; hospital pharmacy of the University Hospital of Zurich, Zurich, Switzerland, andrea.burch@kaz.zh.ch

10.1136/ejhpharm-2021-eahpconf.367

Background and importance Chemicals are subject to mandatory requirements for hazardous substances (GHS; Globally Harmonized System of Classification and Labelling of Chemicals). By contrast, references to measures to protect hospital staff from the hazardous aspects of drugs such as cancerogenicity, mutagenicity or reproductive toxicity (CMR) in the summaries of product characteristics (SPCs) are meagre; intuitive concepts for nurses in a hospital are scarce.

Aim and objectives The aim of this project was first to establish a concept, which assessed the hazards to staff while handling CMR-drugs and second to define appropriate measures based on this, which minimise the exposure to substances with CMR-potential.

Materials and methods To achieve this, an assessment of the intrinsic risk potential of the substances used therapeutically in the hospital was conducted $(1 ; 2)$. After this, the activities using the different dosage forms of CMR-drugs were evaluated and measures for exposure minimisation were specified accordingly.

Results The drugs with CMR-potential have been marked in the drug administration guides provided by the hospital pharmacy of the hospital pharmacy. Additionally, the activities, paired with the diverse dosage forms, have been classified in risk categories from 1 (highest) to 6 (lowest) (own classification; presented as pyramid and flow-chart).

Measures to minimise the risk for staff while handling CMR-drugs were specified according to the STOP principle: substitution, technical/organisational/personal protection measures. The latter are dependent on the classification of the 'dosage form/activity' in the risk categories determined by the hospital pharmacy.

Conclusion and relevance This procedure for the risk assessment of drugs with CMR-potential and the introduction of safety measures depending on the classification of dosage form/activity in risk categories results in a minimisation of the risk to staff while handling these drugs. The risk, which is per definition the product of the risk potential and exposure, tends towards zero with the introduced measures.

\section{REFERENCES AND/OR ACKNOWLEDGEMENTS}

We thank $\mathrm{E}$ Whittome for the very helpful translation of this abstract and B Kissling and P Massarotto for the intense discussions.

1. IARC. Agents Classified by the IARC Monographs. volumes 1-123. [Online] https://monographs.iarc.fr/list-of-classifications-volumes/.

2. National Institute for Occupational Safety and Health (NIOSH). List of Antineoplastic and Other Hazardous Drugs in Healtcare Settings. [Online] 2016. https://www. cdc.gov/niosh/docs/2016-161\%. 